\title{
Factors Influencing the Adoption of Mobile Gaming Services
}

Citation for published version (APA):

Kleijnen, M. H. P., de Ruyter, J. C., \& Wetzels, M. G. M. (2002). Factors Influencing the Adoption of Mobile Gaming Services. In BE. Mennecke, \& TJ. Strader (Eds.), Mobile Commerce: Technology, Theory and Applications (pp. 202-217). Idea Group Publishing. https://doi.org/10.4018/978-1-59140-044-8.ch011

Document status and date:

Published: 01/01/2002

DOI:

10.4018/978-1-59140-044-8.ch011

Document Version:

Publisher's PDF, also known as Version of record

\section{Please check the document version of this publication:}

- A submitted manuscript is the version of the article upon submission and before peer-review. There can be important differences between the submitted version and the official published version of record.

People interested in the research are advised to contact the author for the final version of the publication, or visit the DOI to the publisher's website.

- The final author version and the galley proof are versions of the publication after peer review.

- The final published version features the final layout of the paper including the volume, issue and page numbers.

Link to publication

\footnotetext{
General rights rights.

- You may freely distribute the URL identifying the publication in the public portal. please follow below link for the End User Agreement:

www.umlib.nl/taverne-license

Take down policy

If you believe that this document breaches copyright please contact us at:

repository@maastrichtuniversity.nl

providing details and we will investigate your claim.
}

Copyright and moral rights for the publications made accessible in the public portal are retained by the authors and/or other copyright owners and it is a condition of accessing publications that users recognise and abide by the legal requirements associated with these

- Users may download and print one copy of any publication from the public portal for the purpose of private study or research.

- You may not further distribute the material or use it for any profit-making activity or commercial gain

If the publication is distributed under the terms of Article $25 \mathrm{fa}$ of the Dutch Copyright Act, indicated by the "Taverne" license above, 


\title{
Chapter XI
}

\section{Factors Influencing the Adoption of Mobile Gaming Services}

\author{
Mirella Kleijnen ${ }^{1,2}$ and Ko de Ruyter \\ Maastricht University, The Netherlands \\ Martin G. M. Wetzels \\ Technical University, Eindhoven, The Netherlands
}

\begin{abstract}
The current chapter focuses the adoption process of mobile gaming. After providing a brief introduction to the topic of m-commerce and $m$-services, several relevant adoption factors are highlighted. These factors have been researched empirically, via a conjoint study conducted in the Netherlands. The results illustrated a hierarchical importance of the factors identified, whereby perceived risk, complexity, and compatibility were identified as the three main regarded as the factors that are mainly influencing the adoption of mobile gaming applications. Based on these findings, we have provided several managerial implications.
\end{abstract}

\section{INTRODUCTION}

According to recent forecasts, the mobile services industry in Europe will be worth over 76 billion Euro by 2005 (Durlacher, 2001). Experts claim that wireless technology will usher in the next wave of electronic commerce-'mobile commerce' ( $\mathrm{m}$-commerce). Them-commerce industry provides unlimited opportuni- 
ties for business growth, and forward-thinking companies are already integrating mobile commerce into their businesses to establish a vital competitive edge (http:/ /www.mobileinfo.com). In order to accomplish this integration of the wireless Web in a successful way, consumers' acceptance of mobile commerce as a delivery channel is essential. Therefore, itseems critical to examine which factors influence customeradoption and diffusion of this new way of providing services.

Although there are numerous studies in the field of adoption and diffusion of marketing-enablingtechnology(Plouffe, Vandenbosch,\&Hulland,2001;Daghfous, Petrof, \& Pons, 1999; Rogers, 1995; Holak \& Lehman, 1990; Labay \& Kinnear, 1981), previous work has mainly focused on the adoption of products and technology (Verhoef \& Langerak, 2001; Au \&Enderwick, 2000; Eastlick\& Lotz, 1999; Davis, 1989). In contrast, the perspective on services and service-enabling technologies is considerably less pronounced. Despite the fact that several trend studies have been conducted regarding the potential of wireless technology and $3 \mathrm{G}$ services (Durlacher, 2001; UMTS Forum, 2001), there exists a need for more substantive, theory-based research, creating a more in-depth understanding of consumer behavior with regard to $m$-commerce. The current study aims to define critical factors in the adoption of mobile services and determine consumers' preferential structure with regard to this technology.

Our contribution to this encyclopedic book on $\mathrm{m}$-commerce is structured as follows. First, we briefly introduce the field of $m$-commerce and $m$-services to set the scene. Subsequently, based on a literature review of adoption and diffusion theory, several success factors enhancing mobile services adoption are identified. Moreover, mobile entertainment services, such as playing games via hand-held devices, are used as a setting for our research. Consequently, we report on an empirical study that was completed among 99 consumers in The Netherlands. By using a conjoint measurement design, we are able to obtain a detailed insight into consumerpreference structures regardingmobile gaming services. Interpretation of the analysis yields a hierarchy of importance concerning m-services adoption factors. Finally, the chapterconcludes with a discussion of the results and theoretical as well as managerial implications of our study.

\section{MOBILE COMMERCE}

Frequently, $\mathrm{m}$-commerce is viewed as the next frontier in the electronic market place. E-commerce adoption and diffusion has led to widespread acceptance of electronic transactions (May, 2001). It is argued that " $\mathrm{m}$-commerce allows users to access the Internet without needing to find a place to plug in" (http:// whatis.techtarget.com). As a result, it is "the effective delivery of electronic commerce into the consumer's hand, anywhere, using wireless technology" (http:/ 
/www.gsmworld.com). Althoughm-commerce is regularly defined as an extension or nextstep ofe-commerce, it should be acknowledged as a business opportunity with its own distinctive characteristics and functions (http://www.mobileinfo.com) resulting from unique advantages wireless technology holds over wired technology. First, the use of a wireless device enables the user to receive information and conduct transactions anywhere, at anytime, guaranteeing customers virtual and physical mobility (UMTS Forum, 2000). Second, the emergence of locationspecific-based applications will enable the usertoreceive context-specificinformation on which toact. The combination of localization and personalization will create unique possibilities for reaching and attracting customers. Personalized services incorporate customized information, meeting users' preferences, and payment mechanisms that allow for personal information storage, eliminating the need to enter credit card information for each transaction (May, 2001).

A considerable range of mobile services is already available, only to be extended by so-called third generation services based on new wireless technologies such as GRPS and UMTS. In a taxonomy of wireless services, Durlacher (2001) identifies four main categories: communication, information, entertainment, and transaction services. Communication services are the foundation of mobile services. Voice-to-voice application is still the primary service in wireless technology (http://www.itweb.co.za). Further examples are person-to-person messaging and SMS-based services, such as mobile chat.

Information provision is a second fundamental service of $\mathrm{m}$-commerce (Durlacher, 2000). This category includes information services, such as general news, sportnews, financial news, and weatherreports. Newell and Newell-Lemon (2001) mention SmartRay.com as a frustration-saver that delivers personalized flight updates to mobile appliances. Another example of information services is convenient access to product and price comparisons. Customers can use their mobile device to compare product characteristics while shopping in a brick-andmortar store or mall.

A third category, entertainment services, seems to be the most promising application judging from the explosive growth ofi-mode in Japan, which wasmainly driven by entertainment services. Virtually every i-mode user consumes the entertainment services offered. Entertainment services vary from mobile music provision to mobile gambling in virtual casinos (Durlacher, 2001; May, 2001).

Finally, transaction services mainly consist ofm-shopping, m-finance, andmpayment(Durlacher, 2001). Mobile shopping services supply customers with the possibility to purchase anything at any point in time. In parallel a "one-button purchase experience for mobile shopping" will be desirable for mobile customers (Durlacher, 2000). M-finance relates to mobile banking and brokerage. Banks provide mobile banking as an additional distribution channel to electronic banking 
(e-banking). In addition to $\mathrm{m}$-banking, mobile brokerage is expected to becomea major business driver(Durlacher, 2001). Professional as well as private traders can use mobile commerce solutions to access information about stock price development of personalized stock portfolios. Finally, with mobile payment, consumers circumvent the necessity to queue by simply transferring payments through their wireless devices (Tarasewich \& Warketin, 2000).

Presently, the market is dominated by communication services. However, several other service types are predicted to become at least similarly important revenue sources. Although the digital distribution of information is growing extensively, entertainmentservices in particularwill gainmomentum from the end of 2002 onwards, being the most fruitful revenue opportunity in the B2C market. According to recent findings of the Arc Group (2001), the total number of 'mobile gamers' is set to increase from 43 million in 2001 to almost 850 million by 2006 . Onlinemobile games are predicted to exhibitstrong growth, rising from $21.8 \%$ of the total gaming market in 2001 to $43.2 \%$ in 2006 (http://www.arcgroup.com). Durlacher(2001) states that "it is expected that mobile games especially will become the number one service and generate annual revenues of around 8.1 billion by 2005 ."

Therefore, in this chapterwe focus on mobile gaming. Mobile gaming services allow users to play interactive multi-player games (MPG) against other remote users (UMTS Forum, 2000) independent of time and location. M-gaming services serve as leisure time entertainment as well as time-killing activity (May, 2001). Existingmobilegames frequently consistofsimplistic single-playergames(Durlacher, 2000) with poor graphical resolutions (Stone, 2001). Examples of existing games can be found for instance at www.wirelessgames.com or http://www.nokia.com/ games/games_extra.html. However, due to increasing quality of wireless technology, futuremobile gaming services willallowusers an experience similar to the highquality experience provided by existing PC solutions. After this elaboration on mobile commerce and an illustration of its potential impact, we will now continue ourdiscussion by identifying the factors that influencetheactual adoption of mobile services in consumers' daily lives.

\section{CRITICAL FACTORS INTHE ADOPTION PROCESS OF MOBILE SERVICES}

Although little empirical research has been conducted on mobile services so far, there is a broad range of theories and previous studies that may assist in setting up a systematic assessment of critical success factors. Many of the earlier adoption models investigate behavioral characteristics, like perception and attitude, and frequently they integrate innovation literature with other constructs to develop a new 
framework (Akkeren \& Cavaye, 1999). Customer acceptance of mobile commerce can be identified as a technology adoption. Several theories have been developed to investigate technology adoption, of which the Technology Acceptance Model (TAM) (Davis, 1993,1989) is well established throughout the literature (Moon \& Kim, 2001; Karahanna \& Limayem, 2000; Lederer, Maupin, Sena, \& Zhuang, 2000). Central in this model are the notions of ease-of-use and usefulness (Davis, 1986). At the same time, the narrow focus of these concepts prohibits us from examining other potential drivers of $m$-commerce adoption. Alternatively, adoption process theory may provide valuable insights for building a theoretical framework (Eastlick \& Lotz, 1999). Landmark studies in this field are the work of Rogers (1962) on diffusion of innovations, and Bass (1969), who pioneered in developing the first analytical marketing models concerning adoption of innovations (Daghfous etal., 1999). Their work initiated the development of extensive research in this field (Daghfous et al., 1999). Several recentempirical studies have validated adoption theory in relation to a wide range of products (Rogers 1995; Holak \& Lehman, 1990; Labay \& Kinnear, 1981; Ostlund, 1973) and technology(Beatty, Shim, \& Jones, 2001; Plouffe etal.,2001). A large number of studies have investigated the use of electronic commerce, but the field of mobile commerce has been left virtually unexplored. In the currentstudy, the conceptual framework of Rogers (1995) has been expanded by several constructs that influence individuals' adoption decisions. Rogers (1995) has defined five factors that influence rate of adoption: (1) relative advantage; (2) compatibility; (3) complexity; (4) communicability; and (5) triability. In the remainder of this section, these factors - including the additional constructs that were identified-will be explained and applied to the context of mobile gaming.

Relative advantage is the extent to which an innovation is perceived as being better than the idea it supersedes (Rogers, 1995). Consumers are not likely to start using new technology just because it is there. The main advantage of mobile services is that they areaccessible 'anytime, anywhere.' Timekilling displaysone of the goals ofusing mobile entertainmentservices. Playing m-games while traveling to school orwork seems to be increasingly popular(http://www.i-moder.nl).

Compatibility relates to the fit between the innovation and the existing values, pastexperiences, and needs of potential adopters (Rogers, 1995). Contextually, this means addressing the issue of how well mobile services fitinto the respondent's daily activities, comparable to the concept of perceived usefulness defined in the TAMmodel (Davis, 1989). Playing mobile games can for instance fitvery well into the lifestyle of a student, who travels to school for an hour everyday and who has adopted the Internet in his daily activities already.

Complexity, also regularly referred to as ease-of-use, is the extent to which 
an innovation isperceived as relatively difficult to understand and use(Plouffeetal., 2001; Karahanna \& Straub, 1999; Agarwal \& Prasad, 1998; Rogers 1995; Davis, 1989). Complexity in our study relates to the use ofm-services. This can relate for instance to ease of accessing a game, the amount of effort it takes to understand the rules of the game, and how easy it is to find somebody to play the game with.

However, there is another factor related to complexity that might play a role, which is very specific for mobile commerce. We have defined this variable as navigation. Design has been identified before as a critical factor in the success of mobileInternet(Dolan, 2000; Kaasinen, Aaltone, Kolari, Melakoski, \& Laakko, $2000)$. In the present context, design is related to the hand-held device. Several mobile devices make use of touch screens; others use dual thumb navigation buttons. Especially in playing network games, navigation ormaneuvering ergonomics is critical, since it influences the reaction speed of participants. This is a very specific feature that relates to the hand-held devices and not to the mobile services themselves and is therefore explicitly taken into account in this research.

Communicability refers to the extent to which the innovation lends itselffor communication, particularly the extent to which the use of the innovation is observable by others (Verhoef \& Langerak, 2001; Rogers, 1995). This factor resembles social influence, which has been identified as a critical factor in the adoption process by several authors (Karahanna \& Limayem, 2000; Karahanna \& Straub, 1999; Fang, 1998). Usage of innovation, apart from other factors, is often influenced by a social context(Karahanna \& Limayem, 2000; Karahanna \& Straub, 1999). Fang (1998) indicates that social influence and social pressure are strongly linked: social pressure refers to the service usage and choice as the result of influence from supervisors, peers, or others that are highly regarded. It signifies the extent to which an individual believes that an innovation will give him added prestige or status in his relevant community (Plouffe etal., 2001). Consumers might experience theneed to play mobile games in order to feel accepted by their friends.

The last factor identified by Roger(1995) is triability, the degree to which an innovation may be experimented with on a limited basis, but without a large commitment. This is not a realistic factor when discussing mobile services. Considerable effort is necessary for trying mobile services. Consumers have to invest a substantial amount of time to familiarize themselves with WAP portals (the current technology providing mobile services via mobile phones), and to personalize the configurations according to their preferences, e.g., which type of games they like to play. Subsequently, consumers can set their preferences for a specific game. Furthermore, the consumer has to possess a hand-held device capable of mobile gaming. This requires significant monetary investment. Moreover, the mobile service (likenetwork games) and time spent online is charged for. Thereare virtually no trial opportunities for network games. Only a limited number of single- 
player games, such as 'Snake,' are offered as free trial via the Internet. Therefore, the variable triability was not taken into account in the current research.

Frequently, the Rogers taxonomy has been extended to include perceived risk (Eastlick \&Lotz, 1999; Ostlund, 1973). The use of highly personalized and context-based technology is particularly prone to consumer risk perception (Newell \& Newell-Lemon, 2001). Perceived risk is defined as the extent to which risks are attributed to the mobile services. Risk can be recognized as total risk or as a specific type of risk (performance, privacy, or psychosocial risk). The opinions of others about the person adopting an innovation can be considered a psychosocial risk and therefore could be defined as part of perceived risk (Ortt, 1998). However, in the currentstudy psychosocialeffects are enclosed in communicability. Consequently, perceived risk will focus on performance and privacy risk. Performance risk of mobile games can encompass the breakdown of the operator network or the browser in the mobile device. Privacy reflects mistrust in mobile security, butalso relates to customers fearing that their personal information will be misused (Sutherland, 2001). Since consumers have to reveal a substantial amount of personal information while settingtheirWAP configurations, privacy issuesmight play a critical role in the adoption process.

Furthermore, critical mass seems to play an important role in the adoption of mobile services. Critical mass theory states that individuals who have access to multiplecommunication media will generally use the mediummostwidelyavailable within their communication community, even when it is not the medium they prefer (Fang, 1998). Critical mass is defined as the minimal number of adopters of an interactiveinnovation for the furtherrate of adoption to be self-sustaining. Especially interactive innovations (like mobile entertainment services) are dependent on the number of others who have already adopted the innovation (Mahler \& Rogers, 1999). Excitement about mobile gaming is increased with the establishment of critical mass. The main entertainment service of i-mode is network gaming. These network games make it possible to compete against other players, either friend or stranger. As the number of consumers using mobile entertainment increases, the playground transforms into a greater, potentially global arena.

The final factor that is included in our study is payment options. One of the factors mentioned as a critical success factor for $\mathrm{i}$-mode in Japan is a convenient billing system(Dolan, 2000). In the currentmarketplace, there are several payment options available. Consumerscan be charged for the minutes they are online via their mobile device. Another option is that they are charged only for the amount of data they download regardless of the timeneeded to perform the service (e.g., i-mode). In this way, mobile devices can be used to support 'always-on' services (Newell \&Newell-Lemon, 2001). When playing games via a hand-held device, costs could be very diverse. It depends, for instance, on the networkzone, time of day, and kind 
of game (strategy games can take a few minutes or a few hours depending on the competence of the players). All these factors might lead to fluctuating prices. A flat fee on the other hand overcomes the aforementioned obstacles. Now that we have introduced our theoretical framework, the next part of the chapter will continue with an elaboration of the research design and the analysis of the results of the empirical study.

\section{RESEARCHDESIGN}

The main goal of this research is to identify a hierarchy of importance concerning the critical factors influencing the adoption of mobile services. Torealize this research objective, conjoint analysis was seen as the appropriate statistical tool.

\section{Conjoint Analysis}

Conjoint analysis is a technique which allows a set of overall responses to factorially designed stimuli to be decomposed so that the utility of each stimulus attribute can be inferred from the respondents' overall evaluations of the stimuli (Green, Helsen, \& Shandler, 1988). A number of(hypothetical) combinations of service elements can be formulated that will be presented to a sample of customers. According to Lilien and Rangaswamy (1997), the analysis comprises three stages. The first stage is concerned with the design of the study, where the attributes and levels relevant to the product or service category will be selected. In the second stage customers rate the attractiveness of a number of possible combinations of customer service elements. Finally, in the third stage these ratings are used to estimate part-worth utilities, i.e., the utility which is attached to the individual levels of each service element included in the research design. Consequently, an accurate estimate of customer trade-offs between services elements can be obtained.

We used "Adaptive Conjoint Analysis"(ACA) to conduct our conjointstudy. ACA is a PC-based system for conjoint analysis. The term 'adaptive' refers to the fact that the computer-administered interview is customized for each respondent; at each step, previous answers are used to decide which question to ask next, to obtain most of the information about the respondent's preferences. The program allows the researcher to design a computer-interactive interview and administer the interview to respondents. The interview can consider many factors and levels, paying special attention to those the respondent considers most important. Questioning is done in an "intelligent" way; the respondent's utilities are continually reestimated as the interview progresses, and each question is chosen to provide the greatest amount of additional information, given what is already known about the respondent's preferences (Sawtooth, 1985-87). 
The dependent variable in our study was the intention to make use of mobile services. The eightindependentvariables were perceived risk (three levels: norisk, medium, high), relative advantage (three levels: no relative advantage, medium, high), compatibility (three levels: nomatch with currentbehavior/prior experiences, medium match, high match), complexity (three levels: easy, medium, difficult), communicability (three levels: communication with friends, colleagues, family), critical mass (three levels: nobody, some people, a lot of people), navigation (four levels: input via mini-keyboard,normal button system, dual thumb, touch screen), and finally payment options (three levels: minutes online, based on data bytes, flat feepermonth).

\section{Sample}

By means of pseudo-random sampling, a total of 99 respondents were intercepted on the street of a mid-sized city in The Netherlands. Every third person that passed the data collection point was invited to participate in our study. A negligible amount of respondents that were approached refused to participate in the study (3.5\%). Internal validation was achieved by an investigation of the correlation coefficient. This coefficient represents the correlation between the respondent's predicted and actual answers to the calibration concepts. A cut-offpoint of 0.5 was used, which led to a usable sample of 84 respondents. The sample can be described as follows: gender (female: $52.4 \%$, male: $47.6 \%$ ), age ( $18-25$ years: $42.8 \%, 26$ 35 years: $28.6 \%,>35$ years: $28.6 \%$ ), and level of education (at least secondary level: $52.4 \%$, higher level education: $26.2 \%$, university: $21.4 \%$ ). A complete overview of the sample characteristics can be found in Table 1 .

Table 1: Sample Characteristics $(n=84)$

\begin{tabular}{l|l|c} 
Variable & Caterogies & $\%$ \\
\hline Gender & Male & 47.6 \\
Age & Female & 52.4 \\
& $18-25$ years & 42.8 \\
& 26-35 years & 28.6 \\
Level of Education & $>35$ years & 28.6 \\
& At least secondary level & 52.4 \\
& Higher level education* & 26.2 \\
& University & 21.4 \\
\hline \multirow{2}{*}{ *equivalent with polytech level }
\end{tabular}


The adopted sampling procedure gave the researchers the ability to perform face-to-face interviews with the respondents, which was desirable since the conjoint method was used (Green \& Krieger, 1991; Green \& Srinivasan, 1990). The interviewer had theoption to explain the technique carefully, and to make sure the data collection system worked properly (laptops were use to collect the data via the ACA system).

One of the major concerns when using street interview surveys is to ensure the sampling procedure is performed in a manner that the correct respondents are chosen (Bush \& Hair, 1985). In order to avoid respondent bias, the research was completed over a 12-day period that included weekend days and weekdays, and differenthours of the day. Respondents were asked if they were familiar with mobile services before they were invited to complete the survey. Through this procedure, we were assured that theyunderstood the meaning of the factors presented to them in therightcontext.

\section{Analysis and Results}

As was stated before, conjoint analysis allows us to define a hierarchy of importance concerning the critical factors influencing adoption of mobile services. Based on the importance ratings, it can beconcluded that perceived risk is the most important factor in adopting mobile services $(20.69 \%)$, complexity is second in importance (15.19\%), and compatibility ranks third(13.71\%). Payment options $(10.77 \%)$, navigation $(10.73 \%)$, and relative advantage $(10.50 \%)$ seem to be approximately equal in importance. Critical mass (9.86\%) and communicability $(8.51 \%)$ seem to have a weaker impact on the adoption decision.

Table 2: Importance Ratings $(n=84)$

\begin{tabular}{l|r|c|} 
Variable & Importance Ratings & Ranking number \\
\hline Perceived Risk & $20.69 \%$ & 1 \\
Complexity & $15.19 \%$ & 2 \\
Compatibility & $13.71 \%$ & 3 \\
Payment Options & $10.77 \%$ & 4 \\
Navigation & $10.73 \%$ & 5 \\
Relative Advantage & $10.50 \%$ & 6 \\
Critical Mass & $9.86 \%$ & 7 \\
Communicability & $8.51 \%$ & 8 \\
\hline
\end{tabular}




\section{CONCLUSIONS}

This study aimed to define significant factors in the adoption ofmobile gaming services and determine consumers' preferential structure with regard to this technology. Based on the conceptual framework of Rogers (1995), relative advantage, compatibility, complexity, and communicability were incorporated as critical factors. Triability was excluded from the current study. Furthermore, additional constructs that seemed relevant in the present context were identified: navigation, perceived risk, critical mass, and payment options. Based on the analysis, the following conclusions can be drawn. Perceived risk, complexity, and compatibility were identified as the three main factors influencing the adoption of mobile gaming applications. This is consistent with earlier findings from theadoption literature (Verhoef \& Langerak, 2001; Ruyter, Wetzels, \& Kleijnen, 2001) in relation to the wired Web. In particular, risk is the most important reason that consumers avoid engaging in a wireless transaction (Newell \& Newell-Lemon, 2001). Therefore, security and privacy issues should be considered in any effort to introduce new $\mathrm{m}$-services. Complexity is another barrier. Although one of the primary benefits of $\mathrm{m}$-commerce is to make life simpler for consumers (Koranteng, 2000), many new consumers are putoffby the complexity associated withusingmservices. Finally, as technology has become more personal, itneeds to fit into a consumer's lifestyle. Critical mass and communicability seem to have the least influence. These factors relate to the social aspect of mobile services, but our results indicate that firstand foremostm-commerce is regarded as a personal technology.

\section{Limitations and Suggestions for Further Research}

The limitations of this study provide directions for future research and point to several theoretical implications. First, in this study a limited number of factors were taken into account, which is inherent to the nature of conjoint analysis. Consequently, otherrelevantmarketingmix variables such as actual pricelevels thatmight be of importance have been excluded. Furthermore, cross-sectional research provides a snapshot of the variables of interest at one point in time. Longitudinal analysis will possibly show a different emphasis on the importance of certain characteristics. Additionally, the study was conducted in The Netherlands, therefore the results might notbe generalizable to countries where the uptake of mobile commerce has been demonstrated to be faster and more widespread. A further limitation of this research relates to the fact that our research was embedded in the context of mobile gaming. Consequently, the generalizability of our results is limited. Finally, the differentscenarios were presented to the research subjects in atextual format. Testing in a more real-life experimental setting using, for example, different prototypes of mobile devices might provide further validation of results. 


\section{Managerial Implications}

The findings of our study hold several specific implications for managers. Results illustrate the importance of perceived riskrelated to the adoption of mobile gamingservices. Consequently, managers need to focus on diminishingperceived risk and increasing consumer trust in order to increase adoption rates. Issues currently under debate are concerned with the security of transactions and privacy associated with personal information. Golden (2000) acknowledges thatsecuring information from unauthorized access is a vital problem for any network, wired or wireless, since imminent security gaps exist in the presentsecurity framework for mobile business. While wired connections using standards such as TransportLayer Security ensure a secure connection between PC and Web server, GSM and GPRS communication mainly provide data-encryption between mobilephone and transmitter. Several measures are currently being introduced, including securing WAP gateways, sophisticated encryption, digital signatures and Public Key Infrastructure (PKI). Furthermore, Hoffmanetal.(1998) state that mistrustarises from consumers' perceived lack of controlovertheaccess third parties have to their personal information during the onlinenavigation process. Companies can develop privacy statements or employ eTRUST certifications for example, ensuring consumers that their information will be used for identification purposes only.

Although conjointanalysis revealed a major emphasis on perceived risk as the most prevalent factor in the adoption process, other factors should not be ignored by marketers. Complexity was the second most important critical adoption factor. This illustrates a need for information that marketers can fulfill via alternative channels such as television or magazines, informing customers aboutm-services usage. Moreover, the use of relatively uncomplicated services should be encouraged, such as informationservicessimilarto SMS services. Customer acquaintance to this category of m-services will lower the barrier to exploitotherm-services as well. Compatibility to daily lifestyle can be illustrated via different media as well. Consumers need to be educated about the possibilities of m-commerce and the convenience itcan bring them by incorporating itinto their daily routines. Advertising should also focus on the unique advantages of mobile services, thereby not only stressing ubiquity of m-commerce butalso pointing out the opportunities of localization and personalization. The introduction of $3 \mathrm{G}$ technologies will provide numerous opportunities in this area.

An additional factor that will become more prevalent with the introduction of new technologies is paymentoptions. Regardless of the service category customers exploit, $\mathrm{m}$-services are perceived as relatively expensive. With the introduction of new technologies such as GPRS and UMTS, constant connectivity to the Internet will be offered. Payment will more likely be based on the amountof data-download than on the duration of time spent online. Another option providers can offer is a flat 
rate, which will stimulate the use of other mobile services as well. Nevertheless mobile billing will present a challenge to providers, as there is no standard yet concerning billing procedures. A clarification of who charges the consumers is needed-the service content provider or the technology provider.

Attention should be devoted to enhancingnavigation systems, particularly in m-entertainment, but also in other service categories. Current devices typically provide cumbersome navigation via the standard buttons on the device. However, newly introduced devices have implemented enhanced features, such as dual thumb buttons, one-button access for mobile Internet, touch screens, and mobile keyboards. Specifically, M-gaming gadgets like mobile joysticks that can be clipped on the mobile phone have been introduced. A continuation of this trend is expected to create profitable opportunities for marketers.

Critical mass and communicability willmost likelybecome more prevailing factors as mobile technology develops into a more social technology, for instance with the development of(more) sophisticatedmulti-player games. The visibility of mobile services can be increased by offering communities or buddy list options through which customers can alert their peers or invite them to join a game for instance.

\section{ENDNOTES}

1 Correspondence to Mirella Kleijnen, $\mathrm{PhD}$ candidate, Maastricht University, Faculty of Economics and Business Administration, P.O. Box 616, NL6200MD Maastricht, tel. +31.43.3883819, fax: +31.43.3884918, e-mail: m.kleijnen@mw.unimaas.nl.

2 The authors would like to extend their thanks to Jeanien Werkman for her assistance to this study.

\section{REFERENCES}

Agarwal, R., \& Prasad, J. (1999). Are individual differences germane to the acceptance of new information technologies? Decision Sciences, 30(2), 361-391.

Akkeren, J. van, \& Cavaye, A.L.M. (1999). Factors influencing entry-level Internet technology adoption by small business in Australia: An empirical study. Proceedings of the $10^{\text {th }}$ Australian Conference on Information Systems.

Au, A.K., \& Enderwick, P. (2000). A cognitive model on attitude towards technology adoption. Journal of Managerial Psychology, 15(4), 266-282. 
Bass, F.M. (1969). A new product growth model for consumer durables. Management Science, 15 (January), 215-227.

Beatty, R.C., Shim, J.P., \& Jones, M.C. (2001). Factors influencing corporate Web site adoption: A time-based assessment. Information \& Management, 38, 337-354.

Bush, A.J., \& Hair, Jr. J.F.(1985). An assessment of the mall intercept as a data collection method. Journal of Marketing Research, 32 (November), $385-$ 391.

Daghfous, N., Petrof, J. V., \& Pons, F. (1999). Values and adoption of innovations: A cross-cultural study. Journal of Consumer Marketing, 16(4), 314-331.

Davis, F.D. (1986), A Technology Acceptance Model for Empirically Testing New End-User Information Systems: Theory and Results. Doctoral dissertation, Massachusetts Institute of Technology, Boston, MA.

Davis, F.D. (1989). Perceived usefulness, perceived ease of use, and usage of information technology: A replication. MISQuarterly, 16(2), 319-339.

Davis, F.D. (1993). User acceptance of information technology: System characteristics, userperceptions and behavioral impacts. International Journal of Man-Machine Studies, 38,475-487.

Dolan, D.P. (2000). The big bumpy shift: Digital music via mobile Internet. First Monday, 5(12). Retrieved January 10, 2001, from the World Wide Web: http://www.firstmonday.org.

Durlacher. (2000). Mobile Commerce Report. Durlacher Research Ltd. RetrievedMay 20,2001, from the WorldWideWeb: http://www.durlacher.com.

Durlacher. (2001). UMTS Report. Durlacher Research Ltd. Retrieved May 20, 2001, from the World Wide Web: http://www.durlacher.com.

Eastlick, M.A., \& Lotz, S. (1999). Profiling potential adopters and non-adopters of an interactive electronic shopping medium. International Journal of Retail and Distribution Management, 27(6), 209-223.

Fang, K. (1998). An analysis of electronic-mail usage. Computer in Human Behavior, 14(2), 349-374.

Golden, P. (2000). Wireless Security-Part I and II. MforMobile Devices Analysis, October Issue, Retrieved November 21, 2000, from the World Wide Web: http://www.mformobile.com.

Green, P.E., Helsen, K., \& Shandler, B. (1988). Conjoint internal validity under alternative profile presentations. Journal of Consumer Research, 15(3), 392-97.

Green,P.E., \& Krieger,A.M.(1991). Segmentingmarkets with conjoint analysis. Journal of Marketing, 55 (October), 20-31. 
Green, P.E., \& Srinivasan, V. (1990). Conjoint analysis in marketing: New developments with implications for research and practice. Journal of Marketing, 4,3-19.

Hoffman, D.L., Novak, T.P., \& Peralta, M. (1998). Building Consumer Trust in Online Environments: The Case for Information Privacy. Working Paper, Vanderbilt University, 1-10.

Holak, S.L., \& Lehman, D.R. (1990). Purchase intentions and the dimensions of innovation: An exploratory model. Journal of Product Innovation Management, 7, 59-73.

Kaasinen, E., Aaltone, M., Kolari, J., Melakoski, S., \& Laakko, T. (2000). Two approaches to bringing Internet services to WAP devices. Computer Networks, 33, 231-246.

Karahanna, E., \& Limayem, M. (2000). E-mail and v-mail usage: Generalizing across technologies. Journal of Organizational Computing and Electronic Commerce, 10(1), 49-66.

Karahanna, E.\& Straub, D.W. (1999). The psychological origins of perceived usefulness and ease-of-use. Information \& Management, 35, 237-250.

Koranteng (2000). Dial "m" for e-commerce. Advertising Age International, May, 1-24.

Labay, D.G., \& Kinnear, T.C. (1981). Exploring the consumer decision process in the adoption of solar energy systems. Journal of Consumer Research, 8 (December), 271-78.

Lederer, A.L., Maupin,D.J., Sena, M.P., \& Zhuang, Y.(2000). The technology acceptance model and the World Wide Web. Decision Support Systems, $29,269-282$

Lilien, G.L., \& Rangaswamy, A. (1997). Marketing Engineering: ComputerAssisted Marketing Analysis and Planning. Reading, MA: AddisonWesley-Longman.

Mahler,A., \& Rogers, E.M. (1999). The diffusion of interactive communication innovations and the criticalmass: Theadoption of telecommunication services by German banks. Telecommunications Policy, 23, 719-740.

May, P. (2001). Mobile Commerce - Breakthroughs in Application Development: Opportunities, Applications and Technologies of Wireless Business. Cambridge, UK: Cambridge University Press.

Moon, J., \& Kim, Y. (2001). Extending the TAM for a World Wide Web context. Information \& Management, 38, 217-230.

Newell, F., \& Newell-Lemon, K. (2001). Wireless Rules. New York, NY: McGraw-Hill.

Ortt, J.R. (1998). Videotelephony in the Consumer Market. Doctoral dissertation, Delft University of Technology. 
Ostlund,L.E.(1973).Perceivedinnovation attributes aspredictorsofinnovativeness. Journal of Consumer Research, 1 (September), 23-29.

Plouffe, C.R., Vandenbosch, M., \& Hulland, J.(2001). Intermediating technologies and multi-group adoption: A comparison of consumer and merchant adoption intentions toward a new electronic payment system. Journal of Product Innovation Management, 18(2), 65-81.

Rogers, E.M. (1962).Diffusion ofInnovations. New York, NY: The Free Press.

Rogers, E.M. (1995). Diffusion of Innovations (4 ${ }^{\text {th }}$ Edition). New York, NY: The Free Press.

Ruyter, J.C. de, Wetzels, M.G.M., \& Kleijnen, M.H.P. (2001). Customer adoption of e-services: An experimental study. International Journal of Service Industry Management, 12 (2), 184-207.

Sawtooth. (1985-87). ACA System Manual. Sawtooth Software, Inc.

Stone, A. (2001). Mobile gaming update: Can doom rescue m-commerce. $M$ Commerce Times. Retrieved November 20, 2001, from the World Wide Web:http://mcommercetimes.com/Services/185.

Sutherland, E. (2001). Gaining m-trust. M-Commerce Times, February Issue. Retrieved March 19, 2001, from the World Wide Web: http:// www.mcommercetimes.com/Solutions/86.

Tarasewich, P., \& Warketin, M. (2000). Issues in wireless e-commerce. $A C M$ SIGecom Exchanges, 1(1), 19-23.

UMTS Forum. (2000). Enabling UMTS / Third Generation Services and Applications. UMTS Forum Report 11. Retrieved June 20, 2001, from the World Wide Web:http://www.umts-forum.org.

UMTS Forum. (2001). The UMTS Third Generation Market-Phase II: Structuring the Service Revenue Opportunities. UMTS Forum Report 13. Retrieved June 20, 2001, from the World Wide Web: http://www.umtsforum.org.

Verhoef, P.C., \& Langerak, F. (2001). Possible determinants of consumers' adoption of electronic grocery shopping in The Netherlands. Journal of Retailing and Consumer Services, 8, 275-285. 